\title{
Contact Urticaria with Systemic Symptoms due to Hexylene Glycol in a Topical Corticosteroid: Case Report and Review of Hypersensitivity to Glycols
}

\author{
D. Spoerl K. Scherer A.J. Bircher \\ Allergy Unit, Department of Dermatology, University Hospital Basel, Basel, Switzerland
}

\section{Key Words}

Contact urticaria syndrome $\cdot$ Topical

corticosteroids $\cdot$ Hexylene glycol

\begin{abstract}
We report a case of severe contact urticaria with systemic involvement resembling an anaphylactic reaction, following the application of a topical corticosteroid. This was caused by hexylene glycol, an excipient in the formulation. Glycols are widely used in cosmetics, foods and topical and systemic drugs. In particular, glycols are present in many topical drugs used by dermatologists. To our knowledge, this is the first case in the literature of a potentially life-threatening immediate-type reaction in the context of a contact urticaria syndrome due to hexylene glycol. The classification of contact urticaria syndrome and the allergenic potential of glycols are reviewed. Dermatologists should be aware of the contact urticaria syndrome and of the increasing use of glycols in topical drug formulation in order to identify possible adverse reactions.
\end{abstract}

Copyright $\odot 2010$ S. Karger AG, Basel

\section{Introduction}

Topical corticosteroids are used for a broad range of inflammatory skin conditions. Side effects are rare and usually seen after prolonged application over months and years. The most frequent delayed side effects are skin atrophy, hypertrichosis, telangiectasia, steroid-induced acne and flare of perioral dermatitis. Immediate adverse reactions to topical corticosteroids are usually brief and include a burning or itchy sensation. This usually does not lead to a discontinuation of the drug. Coombs type IV, delayed-type hypersensitivity reactions to corticosteroids are well known [1], whereas immediate-type hypersensitivity reactions are very rare. However, the increasing number of patients with positive skin tests (prick and intradermal tests) for glucocorticoids indicates that immediate-type hypersensitivity to glucocorticoids occurs [2-4]. However, only in a few cases, a presence of specific immunoglobulin E (IgE) in reaction to glucocorticoids was documented by the Radio-AllergoSorbent-Test method [5, 6]. Anaphylaxis and death have been reported in reaction to the systemic administration of corticosteroids [7]. There are more than 100 published reports of immediate hypersensitiv- ity reactions occurring after oral and parenteral administration of corticosteroids $[5,8]$. Other than in delayed-type reactions, no clear cross-reactive patterns between corticosteroid classes could be demonstrated in immediate-type reactions [9]. Only one report of anaphylaxis after the use of a topical corticosteroid cream could be found, and it was probably elicited by neomycin, which was present in the formulation [10].

Maibach and Johnson [11] defined the contact urticaria syndrome in 1975; since then, numerous reports of the contact urticaria syndrome caused by a variety of compounds have been reported. The contact urticaria syndrome can be described in two broad categories: nonimmunologic contact urticaria (type A) and immunologic contact urticaria (type B). Examples of type A contact urticaria are the skin reaction seen after exposure to jellyfish or nettles where a histamine release occurs without involving an immunologic process. Type B contact urticaria is less common in clinical practice than nonimmunologic contact urticaria. Type B contact urticaria is a Coombs type I hypersensitivity reaction mediated by IgE antibodies specific to the eliciting substance. Therefore, prior sensitization is required for this

\section{KARGER}

Fax +4161306 1234 E-Mail karger@karger.ch www.karger.com
Andreas J. Bircher, MD

Allergy Unit, Department of Dermatology

University Hospital Basel, Petersgraben 4

$\mathrm{CH}-4031$ Basel (Switzerland)

Tel. +41 61265 4359, Fax +41 61265 5750, E-Mail birchera@ uhbs.ch 


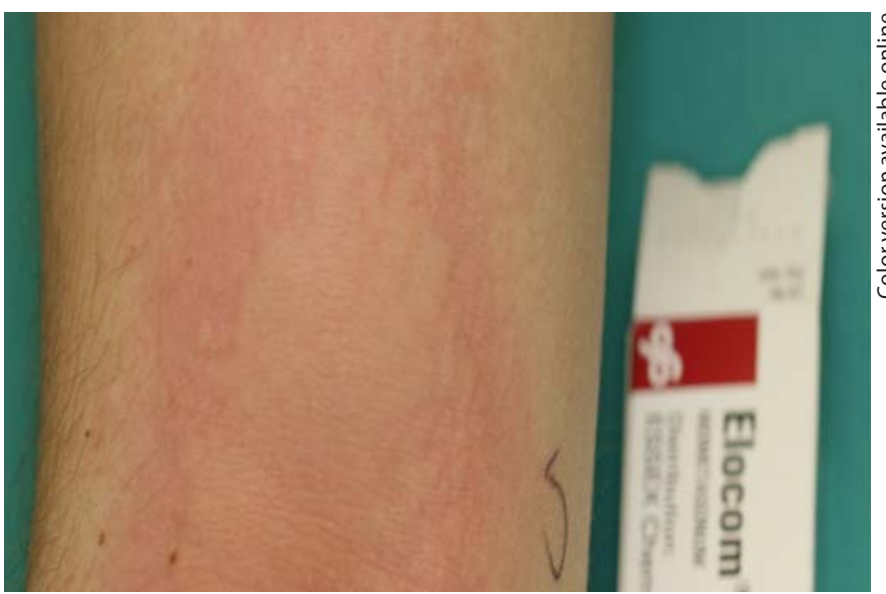

Fig. 1. Contact urticaria $20 \mathrm{~min}$ after open application of Elocom ${ }^{\circledR}$ ointment containing hexylene glycol.

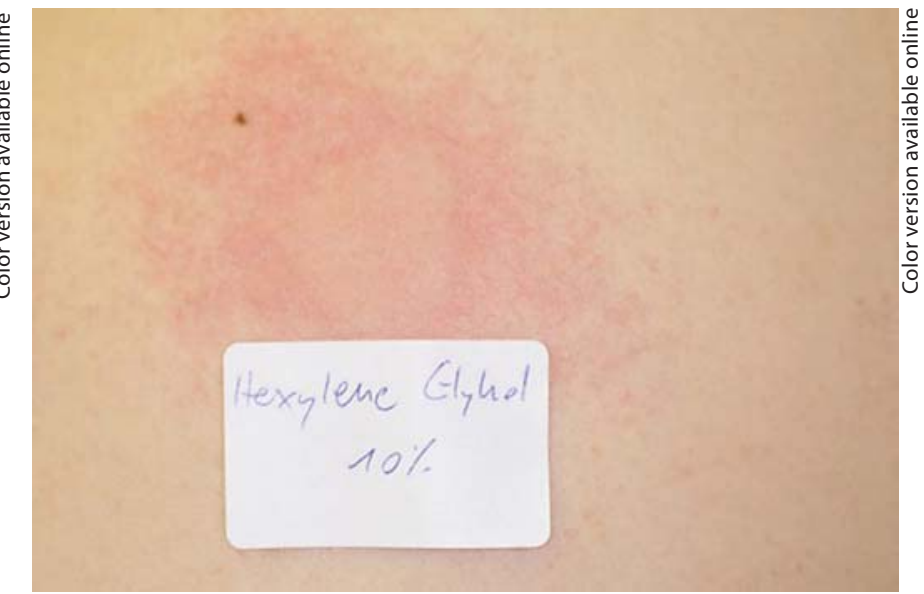

Fig. 2. Contact urticaria after application of hexylene glycol $10 \%$. type. Immunologic contact urticaria reactions may typically spread beyond the site of contact and progress to generalized urticaria. If more severe, immunologic contact urticaria may lead to anaphylactic shock. One such example is immunologic contact urticaria from natural rubber latex.

One year later, Odom and Maibach [12] added a type $\mathrm{C}$ contact urticaria syndrome for those cases where neither an immunologic nor a nonimmunologic mechanism had been identified [13]. Although a histamine release from mast cells is likely to be involved, it is unknown whether degranulation is initiated immunologically or by direct action on the mast cells in those cases [14].

We report a case of contact urticaria with systemic involvement resembling an anaphylactic reaction, following the application of a topical corticosteroid. This was caused by hexylene glycol, an excipient in the formulation. The allergenic potential of glycols is reviewed. Written informed consent was obtained from the patient for the publication of this case report and accompanying images.

\section{Case Report}

In January 2009, a 30-year-old, nonatopic male patient presented to his general practitioner, complaining of burning and dry skin on his back after a holiday in Brazil. He had neither a history of atopic diseases nor of contact hypersensitivity. $\mathrm{He}$ was prescribed topical mometasone furoate cream (class III topical corticosteroid). The same night, he applied the cream on his back for the first time and after a few minutes felt a burning sensation, followed by angioedema (tongue and eyelids) and dyspnea after $45 \mathrm{~min}$. A shower did not relieve the symptoms, and the patient presented to the emergency department where the physician documented an urticarial skin reaction. Angioedema was absent at this point. Two hours later, the patient was dismissed in good condition, eupneic and with a completely abated skin rash after treatment with antihistamines.

One month later, skin prick tests were performed, showing no reaction to common allergens (pollen, house dust mites, pets, molds and latex). An open provocation test with mometasone furoate cream and ointment was performed in both cubital folds. After about $20 \mathrm{~min}$, an urticarial rash appeared on both sides (fig. 1). The common contents of both formulations, the cream and the ointment, are the following: mometasone furoate, hexylene glycol, purified water, phosphoric acid, propylene glycol stearate, white wax and white petrolatum.

Skin prick tests with a topical corticosteroid patch series and Nasonex ${ }^{\circledR}$ (mometasone furoate nasal spray) were negative. Skin prick tests with solid and fluid propylene glycol up to a $50 \%$ concentration were negative. Intracutaneous tests with Macrogol (polyethylene glycol or PEG) 400 and 6000 were also negative for concentrations up to $10 \%$. Prick tests with white petrolatum, PEG DAB 8 and Physiogel $^{\circledR}$ cream (pentylene glycol) were also negative (table 1). A positive reaction was present to pure hexylene glycol (>99\%; product ref. No. 112100-500G, CAS No. 107-41-5; Sigma Aldrich Chemie GmbH, Buchs, Switzerland) in 1 and $10 \%$ concentrations by prick and rub tests (fig. 2). Both were negative in 3 atopic and 2 nonatopic controls. Similarly, Sebiprox shampoo (containing hexylene glycol) showed a urticarial skin reaction $20 \mathrm{~min}$ after open application.

Retrospectively, the patient remembered having reacted in the past to a shampoo with a burning sensation on the head; however, he did not remember the brand name. Blood tests could not be performed due to aichmophobia (panic disorder regarding needles). The patient was advised to avoid hexylene-glycol-containing topical agents and shampoos and had no skin reaction ever since.

\section{Discussion}

Glycols are alcohols containing two hydroxyl groups (diols) (fig. 3). In medicine, PEG are the most widely used glycols. The numbers that are often included in the names of PEG indicate their average molecular weight, e.g. a PEG with an average molecular weight of approximately $400 \mathrm{Da}$ 
Table 1. Name, concentration and application route of tested compounds

\begin{tabular}{|c|c|c|c|}
\hline Compound & Concentration & Prick & Intradermal \\
\hline Amcinonide & $0.1 \%$ & negative & nd \\
\hline Hydrocortisone & $1 \%$ & negative & nd \\
\hline Triamcinolone acetonide & $0.1 \%$ & negative & nd \\
\hline Clobetasol-17-propionate & $0.25 \%$ & negative & nd \\
\hline Hydrocortisone-17-butyrate & $0.1 \%$ & negative & nd \\
\hline Betamethasone-17-valerate & $0.12 \%$ & negative & nd \\
\hline Budesonide & $0.1 \%$ & negative & nd \\
\hline Prednisolone & $1 \%$ & negative & nd \\
\hline Dexamethasone-21-phosphate disodium salt & $1 \%$ & negative & nd \\
\hline Tixocortol pivalate & $1 \%$ & negative & nd \\
\hline Propylene glycol & $50 \%$ & negative & nd \\
\hline Propylene glycol & $25 \%$ & negative & nd \\
\hline Propylene glycol & $5 \%$ & negative & nd \\
\hline Propylene glycol monostearate Tesal & pure (solid) & negative & nd \\
\hline Propylene glycol monostearate Nikkol & pure (solid) & negative & nd \\
\hline Propylene glycol monostearate Radiasurf & pure (solid) & negative & nd \\
\hline Propylene glycol monostearate Monosteol & pure (solid) & negative & nd \\
\hline Macrogol 400 & $1: 10,000$ of $10 \%$ & nd & negative \\
\hline Macrogol 400 & $1: 1,000$ of $10 \%$ & nd & negative \\
\hline Macrogol 400 & $1: 100$ of $10 \%$ & nd & negative \\
\hline Macrogol 400 & $1: 10$ of $10 \%$ & nd & negative \\
\hline Macrogol 400 & $10 \%$ & nd & negative \\
\hline Macrogol 6000 & $1: 10,000$ of $10 \%$ & nd & negative \\
\hline Macrogol 6000 & $1: 1,000$ of $10 \%$ & nd & negative \\
\hline Macrogol 6000 & $1: 100$ of $10 \%$ & nd & negative \\
\hline Macrogol 6000 & $1: 10$ of $10 \%$ & nd & negative \\
\hline Macrogol 6000 & $10 \%$ & nd & negative \\
\hline White wax & pure & negative & nd \\
\hline Nasonex $^{\circledR}$ (mometasone furoate) & pure & negative & nd \\
\hline Propylene glycol & $5 \%$ & negative & nd \\
\hline PEG cream & $100 \%$ & negative & nd \\
\hline Benzalkonium chloride & $0.1 \%$ & negative & nd \\
\hline Physiogel ${ }^{\circledR}$ cream (pentylene glycol) & pure & negative & nd \\
\hline Sebiprox ${ }^{\circledR}$ shampoo (containing hexylene glycol) & pure & positive & nd \\
\hline Elocom ${ }^{\circledR}$ cream (containing hexylene glycol) & pure & positive & nd \\
\hline Hexylene glycol & $1 \%$ & positive & nd \\
\hline Hexylene glycol & $10 \%$ & positive & nd \\
\hline
\end{tabular}

Positive $=$ Urticarial reaction; nd $=$ not done .

would be labeled PEG 400. With increasing chain length, the preparation takes on the characteristics of a gel rather than a liquid [15]. The monomer, ethylene glycol, is notoriously toxic, being the solvent used in an 'elixir' that killed over 100 people in 1937 [15]. Toxicity has been reported for propylene glycol and PEG in parenteral administration, especially at high doses and in patients with renal impairment [15].

PEG are the basis of a number of laxatives, skin creams and sexual lubricants, frequently combined with glycerine. They are also used in a number of toothpastes as a dispersant; they bind water and help to retain a uniform distribution of gum in the toothpaste. When attached to various protein medications, e.g. PEG-interferon$\alpha$, PEG slows the clearance of the therapeutic protein, allowing longer dosing intervals. A conjugation of allergens with PEG often increases tolerogenity [16-18]. This has been studied in immunotherapy $[18,19]$ and more recently in drug develop- ment [20]. Paradoxically, PEG also have a potential to cause immediate-type hypersensitivity reactions [21-23]. Anaphylaxis, asthma, angioedema and urticaria have been described after the administration of oral PEG electrolyte lavage solutions [2427]. Recently, anaphylaxis has also been reported after tablets and intraarticular corticosteroid injections where PEG was used as a vehicle and an excipient, respectively $[23,28]$. Phadia AB (Uppsala, Sweden) has recently developed a modified 


$$
{ }_{\mathrm{PEG}}^{\mathrm{H}} \Upsilon_{\mathrm{O}} \sim_{\mathrm{PG}}^{\mathrm{OH}} \overbrace{\mathrm{OH}}^{\mathrm{CH}_{3}} \overbrace{\mathrm{HG}} \overbrace{\mathrm{CH}_{3}}^{\mathrm{OH}} \mathrm{CH}_{3}
$$

Fig. 3. Formulas of PEG, propylene glycol $(\mathrm{PG})$ and hexylene glycol (HG).

version of the IgE and IgG antibody ImmunoCAP assay for measuring antibodies to PEG. Seven patients were tested, all with negative specific IgE [Rosengren P., pers. commun., June 17, 2009].

Propylene glycol (propane-1,2-diol) belongs to the vicinal diols having hydroxyl groups attached to adjacent atoms (fig. 3). Propylene glycol is used as a humectant food additive (E1520), as a moisturizer in cosmetics, food, toothpaste, mouth wash and tobacco products, as the main ingredient in deodorant sticks, as an antifreeze liquid and as a solvent in many pharmaceuticals including oral, injectable and topical formulations. Notably, in diazepam, which is insoluble in water, propylene glycol is used as a solvent in its injectable form.

Hexylene glycol (2-methyl-pentane2,4-diol) (fig. 3) is mainly found in industrial coatings (paints, lacquers and varnishes), in leather and textile processing as a moistening and softening agent, in antifreeze fluids, and in cosmetics and topical drugs (especially topical corticosteroids) at concentrations between 0.1 and $25 \%$. Hexylene glycol is not as widely used as pentylene glycol in dermatological products [29], but is an ingredient in the corticosteroid preparation of Elocom (Schering-Plough).

Propylene glycol and hexylene glycol seem to act as sensitizers in contact allergy [30-33], i.e. delayed-type hypersensitivity reactions. In this context, cross-reactivity between propylene glycol and hexylene glycol has been described [34].

The incidence of propylene glycol contact allergy among patients with eczema has been evaluated to be greater than $2 \%$ [35]. Contact dermatitis in reaction to propylene glycol in calcipotriene ointment and an ultrasonic gel [36-39], as well as in an antiviral cream (Zovirax $\left.{ }^{\circledR}\right)$ [40], has been reported. Flares of contact dermatitis following the ingestion of foods containing propylene glycol have been noticed [30], and systemic contact dermatitis due to intravenous propylene glycol in diazepam $\left(\right.$ Valium $^{\circledR}$ ) in a patient sensitized to propylene glycol has been reported [41]. One report described contact urticaria in reaction to a corticoid cream containing propylene glycol, the responsible chemical, however, was found to be polysorbate 60 , a mixture of stearate ester of sorbitol and sorbitol anhydrides [42]. Contact urticaria could not be observed in experiments with open propylene glycol application [43]; only one report describes nonimmunologic contact urticaria after topical propylene glycol application [44].

Less is known about the incidence of hypersensitivity to hexylene glycol. In a first human study, 5 human subjects were given oral doses of $37 \mathrm{~g}$ of hexylene glycol daily for 24 days (estimated daily dosage: 14-28 $\mathrm{mg} / \mathrm{kg}$ body weight). No subjective symptoms that could be attributed to the intake of hexylene glycol were reported [45]. First clues pointing to a sensitizing potential were seen in patch tests where hexylene glycol (10\% aqueous) was tested in a group of 230 patients with occupational dermatitis in the metallurgic industry. Nine patients had a positive patch test with hexylene glycol $(3.9 \%$ of the total number tested) [33]. An unclear reaction was reported in $2.8 \%$ of 823 eczema patients tested by patch tests with hexylene glycol at aqueous concentrations of 30 or $50 \%$ (48- hour occlusion): they showed edema and erythema of the skin; the authors considered this indicative of an irritation rather than a contact allergy [46]. In a further study, mometasone furoate $0.1 \%$ fatty cream (containing hexylene glycol, as in the present case) was applied twice weekly for 6 months. Among the 68 patients with atopic dermatitis, 4 showed adverse events related to the treatment: 2 showed folliculitis, 1 skin atrophy and 1 sensation of increased warmth [47]. It has not been mentioned whether the last was an urticarial skin reaction or not. Otherwise, so far no reports are present in the literature describing an immediate-type reaction to hexylene glycol.

Our patient had a contact urticaria with systemic involvement following the application of a topical corticosteroid cream due to hexylene glycol which was present in the formulation. An open application of diluted pure hexylene glycol elicited contact urticaria, confirming its causative role. The systemic involvement and the possibility of a previous exposure and sensitization in our patient together with the negative tests in the controls favor an immunologically mediated process, but this could not be supported by specific IgE. Because no immunological test could be performed due to severe aichmophobia in our patient, the pathogenetic process could not be further elucidated. Therefore, we consider this to be a type $\mathrm{C}$ contact urticaria syndrome. In our tests with other glycols, no cross-reactivity to propylene glycol or PEG could be detected. With strict avoidance of hexylene glycol contact, the patient remained free of symptoms.

\section{Acknowledgment}

We thank Christian Surber, Spirig Inc., for providing samples of propylene glycol monostearate.
References

Contact Urticaria and Hexylene Glycol
Baeck M, Chemelle JA, Terreux R, Drieghe J, Goossens A: Delayed hypersensitivity to corticosteroids in a series of 315 patients: clini$\mathrm{cal}$ data and patch test results. Contact Dermatitis 2009;61:163-175.

-2 Rytter M, Walther T, Süss E, Haustein UF: Allergic reactions of the immediate and delayed type following prednisolone medication. Dermatol Monatsschr 1989;175:44-48.
Caduff C, Reinhart WH, Hartmann K, Kuhn M: Immediate hypersensitivity reactions to parenteral glucocorticoids? Analysis of 14 cases. Schweiz Med Wochenschr 2000;130: 977-983.

4 Erdmann SM, Abuzahra F, Merk HF, Schroder A, Baron JM: Anaphylaxis induced by glucocorticoids. J Am Board Fam Pract 2005;18:143-146. 
5 Cheam H, Butani L: Immunoglobulin E-mediated reactions to corticosteroids. Curr Allergy Asthma Rep 2005;5:22-27.

-6 Burgdorff T, Venemalm L, Vogt T, Landthaler M, Stolz W: IgE-mediated anaphylactic reaction induced by succinate ester of methylprednisolone. Ann Allergy Asthma Immunol 2002;89:425-428.

7 Kamm GL, Hagmeyer KO: Allergic-type reactions to corticosteroids. Ann Pharmacother 1999;33:451-460.

-8 Gonzalo FE, Montagut LB, Vecina ST: Anaphylactic shock caused by triamcinolone acetonide. Ann Pharmacother 1994;28:1310.

$\checkmark 9$ Venturini M, Lobera T, del Pozo MD, González I, Blasco A: Immediate hypersensitivity to corticosteroids. J Investig Allergol Clin Immunol 2006;16:51-56.

10 Pippen R: Anaphylactoid reaction after chymacort ointment. Br Med J 1966;1:1172.

-11 Maibach HI, Johnson HL: Contact urticaria syndrome: contact urticaria to diethyltoluamide (immediate-type hypersensitivity). Arch Dermatol 1975;111:726-730.

12 Odom RB, Maibach HI: Contact urticaria: a different contact dermatitis. Cutis 1976;18: 672-676.

13 de Groot AC: The contact urticaria syndrome; in de Groot AC, Weyland JW, Nater JP (eds): Unwanted Effects of Cosmetics and Drugs Used in Dermatology, ed 3. Amsterdam, Elsevier Science, 1994, pp 155-164.

14 von Krogh G, Maibach HI: The contact urticaria syndrome: an updated review. J Am Acad Dermatol 1981;5:328-342.

15 Murray W: Adverse effects: bulk materials; in Murray W, Bernstein IL (eds): Adverse Reactions to Drug Formulation Agents. A Handbook of Excipients. New York, Marcel Dekker Inc., 1989, pp 101-111.

-16 Saito T, Nishimura H, Sekine T, Urushibara T, Kodera Y, Hiroto M, Matsushima A, Inada Y: Tolerogenic capacity of poly(ethylene glycol) (PEG)-modified ovalbumins in relation to their immunoreactivity towards antiovalbumin antibody. J Biomater Sci Polym Ed 1996;8:311-321.

-17 Saito T, Kumagai Y, Hiramatsu T, Kurosawa M, Sato T, Habu S, Mitsui K, Kodera Y, Hiroto $M$, Matsushima $A$, Inada $Y$, Nishimura $\mathrm{H}$ : Immune tolerance induced by polyethylene glycol-conjugate of protein antigen: clonal deletion of antigen-specific Th cells in the thymus. J Biomater Sci Polym Ed 2000; 11:647-656.

18 Dreborg S, Akerblom EB: Immunotherapy with monomethoxypolyethylene-glycolmodified allergens. Crit Rev Ther Drug Carrier Syst 1990;6:315-365.
19 Mosbech H, Djurup R, Dreborg S, Kaergaard Poulsen L, Stahl Skov P, Steringer I: Hyposensitization in asthmatics with $\mathrm{mPEG}$ modified and unmodified house dust mite extract. 3. Effect on mite-specific immunological parameters and correlation to changes in mite-sensitivity and symptoms. Allergy 1990;45:130-141.

20 Baird EJ, Holowka D, Coates GW, Baird B: Highly effective poly(ethylene glycol) architectures for specific inhibition of immune receptor activation. Biochemistry 2003;42: 12739-12748.

21 Fisher AA: Contact urticaria due to polyethylene glycol. Cutis 1977;19:409-412.

22 Antón Gironés M, Roan Roan J, de la Hoz B, Sánchez Cano M: Immediate allergic reactions to PEG 4000: two cases. Allergol Immunopathol (Madr) 2008;36:110-112.

23 Dewachter P, Mouton-Faivre C: Anaphylaxis to macrogol 4000 after a parenteral corticoid injection. Allergy 2005;60:705-706.

24 Stollman N, Manten HD: Angioedema from oral polyethylene glycol electrolyte lavage solution. Gastrointest Endosc 1996;44:209210.

25 Schuman E, Balsam PE: Probable anaphylactic reaction to polyethylene glycol electrolyte lavage solution. Gastrointest Endosc 1991;37: 411.

26 Pariente EA, Piot M, Delvert D, Benichou M, Barbe S: Asthma and skin rash after preparation to colonoscopy with a flavored polyethylene glycol solution. Gastroenterol Clin Biol 1992;16:614-615.

27 Coschieri M, Philippon A, Longo F, Carmignani S, Quinsat D, Dor JF: Urticaria after ingestion of polyethylene glycol. Gastroenterol Clin Biol 1994; 18:538.

28 Hyry H, Vuorio A, Varjonen E, Skyttä J, Mäkinen-Kiljunen S: Two cases of anaphylaxis to macrogol 6000 after ingestion of drug tablets. Allergy 2006;61:1021.

29 Sundberg JJ, Faergemann J: A comparison of pentane-1,5-diol to other diols for use in dermatology. Expert Opin Investig Drugs 2008; 17:601-610.

30 Lowther A, McCormick T, Nedorost S: Systemic contact dermatitis from propylene glycol. Dermatitis 2008;19:105-108.

31 Lessmann H, Schnuch A, Geier J, Uter W: Skin-sensitizing and irritant properties of propylene glycol. Contact Dermatitis 2005; 53:247-259.

- 32 Warshaw EM, Botto NC, Maibach HI, Fowler JF Jr, Rietschel RL, Zug KA, Belsito DV, Taylor JS, DeLeo VA, Pratt MD, Sasseville D, Storrs FJ, Marks JG Jr, Mathias CG: Positive patch-test reactions to propylene glycol: a retrospective cross-sectional analysis from the North American Contact Dermatitis Group, 1996 to 2006. Dermatitis 2009;20: 14-20.
-33 Alomar A, Conde-Salazar L, Romaguera C: Occupational dermatoses from cutting oils. Contact Dermatitis 1985;12:129-138.

34 de Groot AC: Allergic contact dermatitis; in de Groot AC, Weyland JW, Nater JP (eds): Unwanted Effects of Cosmetics and Drugs Used in Dermatology, ed 3. Amsterdam, Elsevier Science, 1994, p 21.

35 Catanzaro JM, Smith JG Jr: Propylene glycol dermatitis. J Am Acad Dermatol 1991;24:9095.

36 Fowler JF Jr, Fowler L, Douglas JL, Thorn D, Parneix-Spake A: Skin reactions to pimecrolimus cream $1 \%$ in patients allergic to propylene glycol: a double-blind randomized study. Dermatitis 2007; 18:134-139.

37 Fisher DA: Allergic contact dermatitis to propylene glycol in calcipotriene ointment. Cutis 1997;60:43-44.

38 Horiguchi Y, Honda T, Fujii S, Matsushima S, Osaki Y: A case of allergic contact dermatitis from propylene glycol in an ultrasonic gel, sensitized at a leakage skin injury due to transcatheter arterial chemoembolization for hepatocellular carcinoma. Int J Dermatol 2005;44:681-683.

-39 Gonzalo MA, de Argila D, García JM, Alvarado MI: Allergic contact dermatitis to propylene glycol. Allergy 1999;54:82-83.

40 Claverie F, Giordano-Labadie F, Bazex J: Contact eczema induced by propylene glycol: concentration and vehicle adapted for patch tests. Ann Dermatol Venereol 1997; 124:315-317.

-41 Fisher AA: Systemic contact dermatitis due to intravenous Valium in a person sensitive to propylene glycol. Cutis 1995;55:327-328.

42 Maibach H, Conant M: Contact urticaria to a corticosteroid cream: polysorbate 60 . Contact Dermatitis 1977;3:350-351.

43 Funk JO, Maibach HI: Propylene glycol dermatitis: re-evaluation of an old problem. Contact Dermatitis 1994;31:236-241.

44 Andersen KE, Storrs FJ: Skin irritation caused by propylene glycols. Hautarzt 1982; 33:12-14.

45 Jacobsen E: The excretion of hexylene glycol (2-methyl-2,4-pentane diol) in man. Acta Pharmacol Toxicol (Copenh) 1958;14:207213.

46 Kinnunen T, Hannuksela M: Skin reactions to hexylene glycol. Contact Dermatitis 1989; 21:154-158.

- 47 Faergemann J, Christensen O, Sjövall P, Johnsson A, Hersle K, Nordin P, Edmar B, Svensson A: An open study of efficacy and safety of long-term treatment with mometasone furoate fatty cream in the treatment of adult patients with atopic dermatitis. J Eur Acad Dermatol Venereol 2000;14:393-396. 